Public Health

\section{Campylobacter and bacterial gastroenteritis}

1 ampylobacter is the most common cause of bacterial gastroenteritis in the developed world. ${ }^{1}$ In Canada, where the disease is reportable, 9345 cases (30.2 per Ioo ooo) of campylobacteriosis were reported in 2004, as compared with 4953 cases of salmonellosis (I6.0 per Ioo o0o). ${ }^{2}$ Reported cases represent only a fraction of the actual number. The highest rates are observed among children less than 5 years old and young adults, particularly men, aged 20-29 years (Box I). ${ }^{2}$ The rates of Campylobacter infection have been declining in Canada and in many developed countries in the last 5-ro years. ${ }^{2}$ The reasons for this are not clear, but they may be due to improvements in food safety.

In developing countries, the disease is mostly confined to young children owing to early exposure to contaminated drinking water and close contact with farm animals. ${ }^{1}$ Campylobacter is one of the most common causes of diarrhea in Canadian travellers to developing countries. ${ }^{1}$

Symptoms occur I-Io days after exposure. Illness is characterized by diarrhea, which may be bloody, abdominal pain, which may be severe and may mimic appendicitis, fever and, rarely, vomiting. ${ }^{1}$ Some patients may be asymptomatic. Illness usually resolves within 2-5 days but may last up to several weeks. Post-infectious complications such as reactive arthritis and Guillain-Barré syndrome occur in

Box 1: Risk factors for Campylobacter infection

- Age $<5$ years and 20-29 years

- Male sex

- Handling and consumption of raw or undercooked poultry and other meats

- Consumption of unpasteurized milk and dairy products

- Consumption of untreated water

- Contact with pets and farm animals

Farm

Kitchen Individual

- Handwashing about $\mathrm{I} \%$ and $0 . \mathrm{I} \%$ of infections, respectively. ${ }^{1}$ About $5 \%-$ Io\% of patients require admission to hospital, and 5 in Io ooo die.

Because the clinical presentation is similar to that caused by other bacterial enteric pathogens, diagnosis of campylobacteriosis is not possible on the basis of symptoms alone. It is done through isolation of Campylobacter in stool specimens with the use of selective media.

Treatment is usually supportive. Antibiotic treatment can be considered if the patient has severe or prolonged symptoms. The drugs of choice include erythromycin and azithromycin. Ciprofloxacin resistance increased in human Campylobacter isolates after the licensure of fluoroquinolones for use in farm animals internationally. ${ }^{1}$ Although fluoroquinolones are no longer used in poultry in Canada, resistance levels remain relatively high.

Campylobacter leads mostly to sporadic infections. About $50 \%$ of cases are associated with the handling and consumption of poultry. Other causes include the consumption of beef, pork, raw milk and contaminated water and contact with pets and farm animals. ${ }^{1}$ Outbreaks have been reported infrequently and most have been associated with contaminated drinking water, such as the outbreak of infection from Escherichia coli Or57:H7 and Campylobacter in Walkerton, Ont., in 2000. Outbreaks have also occurred among men who have sex with men.

In Canada, about $95 \%$ of cases are caused by Campylobacter jejuni, $4 \%$ by Campylobacter coli and $\mathrm{I} \%$ by other Campylobacter species. C. jejuni is primarily isolated from poultry but also from cattle, sheep, goats, pets and wildlife. $C$. coli is most often isolated from swine. Drinking water can become contaminated by animal waste.

It is unclear why the rates of campylobacteriosis are higher than those of other types of bacterial gastroenteritis. Campylobacter infection spreads very easily among poultry at the farm level; poultry are believed to act as an amplifier of Campylobacter. Up to $90 \%$ of poultry flocks are colonized in some European countries. ${ }^{1}$ In British Columbia, during the summers of 2005 and $2006,41 \%-59 \%$ of flocks were infected with Campylobacter, as compared with I2\%-I4\% with Salmonella (Dr. Jane Pritchard, BC Ministry of Agriculture and Lands: personal communication, 2007). In Canada, 37\%$5 \mathrm{I} \%$ of retail chicken has been found to be contaminated with Campylobacter, as compared with only 10\%-I7\% with Salmonella. ${ }^{3}$

Infection control measures need to be taken along the farm-to-fork continuum (Box 2). At the farm level, biosecurity measures help decrease transmis-

Box 2: "Farm-to-fork" strategies for preventing Campylobacter infection

- Ensuring animal health through preventive and veterinary medicine

- Ensuring biosecurity (e.g., appropriate cleaning and ventilation, safe handling of litter and manure, elimination of standing water)

Slaughterhouse and processing

- Maintaining good hygiene and sanitation

- Using HACCP (Hazard Analysis and Critical Control Points)

- Separating contaminated from uncontaminated animals and meat

- Keeping poultry and meat refrigerated

- Avoiding cross-contamination

- Cooking poultry to an internal temperature of $74^{\circ} \mathrm{C}$ and meats to $71^{\circ} \mathrm{C}$ 
sion between animals and between flocks and herds. During slaughter, good hygiene and the separation of infected from noninfected animals decrease the risk of cross-contamination. In some Scandinavian countries, strict poultry farm and processing measures have been implemented, and a decline in human Campylobacter infection rates has subsequently been observed.

In the kitchen, care should be taken to avoid direct and indirect (through common utensils and surfaces) contact between raw meat and other uncooked foods and to cook poultry and meat thoroughly. Food handlers should be excluded from work while symptomatic. Travellers should avoid raw milk and dairy products, eat only wellcooked meat and drink boiled or bottled water. Everyone should wash their hands after contact with raw meats and animals.

In summary, Campylobacter infection should be suspected in a patient with acute diarrhea and severe abdominal pain. A cluster of cases of campylobacteriosis or the suspicion that a patient drank contaminated water should be reported immediately to the local public health unit for investigation. The most effective way individuals can prevent Campylobacter infection is to drink treated water and pasteurized milk, adequately cook meats and avoid cross-contamination of foods in the kitchen.

\section{Eleni Galanis MD MPH}

BC Centre for Disease Control

Vancouver, BC

This article has been peer reviewed.

Competing interests: None declared.

\section{REFERENCES}

I. Nachamkin I, Blaser MJ, eds. Campylobacter. 2nd ed. Washington: ASM Press; 2000.

2. Notifiable diseases online. Ottawa: Public Health Agency of Canada. Available: http://dsol-smed.phac -aspc.gc.ca/dsol-smed/ndis/index_e.html (accessed 2007 May 3).

3. Canadian Integrated Program for Antimicrobial Resistance Surveillance. Recovery rate and final number of isolates submitted for antimicrobial resistance (AMR) testing across the bacterial species, the active surveillance components and the animal species, 2002-2005. Ottawa: Public Health Agency of Canada. Available: www.phac-aspc.gc.ca/cipars -picra/pdf/cipars-picra-2005_pr-tı_e.pdf (accessed 2007 May 8). 